\title{
Effective Chemical Cleaning of a Cross-Flow Nanofiltration Membrane Fouled by Dye Solution-Conditional Experimental Study
}

\author{
Jigesh Mehta* \\ Department of Chemical Engineering, School of Engineering, P P Savani University, kosamba, India
}

*Corresponding author: Jigesh Mehta, Assistant Professor, Department of Chemical Engineering, School of Engineering, P P Savani University, kosamba, India

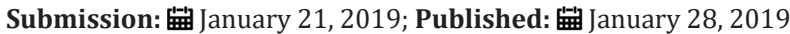

\begin{abstract}
Filtration of water is one of the conventional techniques implemented worldwide in the $18^{\text {th }}$ century to meet the basic requirements of human kind. Quality and Purity of water is major concern today as water is depleting day by day. Concept of recycle and reuse will only meet the demand when used membrane is being regenerated and reused. For the regeneration purpose, cleaning of surface is mandatory. This article experimentally discusses the cleaning reagent especially $\mathrm{NaOH}$ as prominent and acceptable tool for the HPA- 250 membrane material to remove the adhere dye particles at different pressure [1 and 2 bar]. Permeate flux calculation provide the conclusive remark as recovery is maximum at higher pressure value [ 2 bar] as $47.22 \%$ while $31.44 \%$ is flux recovery at 1 bar pressure provided the condition of solute concentration constant.
\end{abstract}

Keywords: Chemical cleaning; Nanofiltration; NaOH reagent; Permeate flux recovery

\section{Introduction}

Due to continuous industrialization and requirement of water in the allied industries, water scarcity is the major problem to the society. Conventional techniques concentrate [filtrates] the waste water generated by industries to such extent that it can be useful on economical scale but when it comes utilization of water for the quality and high valued products, this method fail to meet the requirements and birth of advanced separation comes into play. Membrane separation processes is one of the most acceptable technique in purifying the unused or waste water to large extent. Advanced techniques have good hope on quality and purity but on the other hand, they losses when it comes its operational cost [1] Membrane itself is one of the costliest polymeric material which once used cannot be utilized for the other separation system. Thus, reusability of such material is required. Chemical cleaning is always most economical technique for serving the purpose of today's era. The work here unfolds the experimental study for the fouling strategies applied on the laboratory scale and then cleaning the same by chemical reagents to meet the conditional requirement to acceptable limits.

\section{Materials and Methods}

\section{Chemicals used}

Fluorescein dark red dye with molecular weight 332.31g. $\mathrm{mol}^{-1}$ was used in the experiment. The solutions of different concentrations of Fluorescein dark red dye were prepared by dissolving accurately weighed dye in tap water. The chemical structure and properties of the dye is given in Table 1.
Table 1: Characteristic properties of the dye used in the experiment.

\begin{tabular}{|c|c|c|c|}
\hline $\mathrm{Sr}$ & \multicolumn{2}{|c|}{ Properties } & \multirow[t]{6}{*}{ Structure } \\
\hline 1 & $\begin{array}{l}\text { Chemical } \\
\text { formula }\end{array}$ & $\mathrm{C}_{20} \mathrm{H}_{12} \mathrm{O}_{5}$ & \\
\hline 2 & Molar mass & $\begin{array}{c}332.31 \mathrm{~g} . \\
\mathrm{mol}^{-1}\end{array}$ & \\
\hline 3 & Density & $1.602 \mathrm{~g} / \mathrm{ml}$ & \\
\hline 4 & $\begin{array}{l}\text { Melting } \\
\text { point }\end{array}$ & $\begin{array}{c}314 \text { to } 316 \\
{ }^{0} \mathrm{C}\end{array}$ & \\
\hline 5 & $\begin{array}{c}\text { Solubility In } \\
\text { water }\end{array}$ & Slightly & \\
\hline
\end{tabular}

\section{Membrane used}

Hydrophilized polyamide [HPA - 250] membrane with MWCO $250 \mathrm{Da}$ and of thickness $125 \mu \mathrm{m}$ with support cloth was used in the study. The membrane was supplied by $\mathrm{M} / \mathrm{s}$ Perm Ionics Membrane Pvt. Ltd, Baroda, India. It is a thin film composite membrane element consisting of a nonwoven polyester substrate on which a polyether sulfone layer is coated [2]. The membrane was prepared by solution casting and phase inversion gelling. The effective membrane area and pore size distribution is $0.016 \mathrm{~m}^{2}$ and $7 \pm 1 \mathrm{~nm}$ respectively.

\section{Experimental setup \& operational conditions}

The experimental setup is schematically illustrated in Figure 1. Experimental setup is divided in five Sections. [A] Equipment 
Section, [B] Instrument Section, [C] Manual Valve Section, [D] Control Panel Section, [E] Permeate Line. Section [A] includes Feed tank [Capacity 5 Liters], Feed Pump [Diaphragm type: 180lph @ 70 bar] and NF Housing with membrane [1.8"D *12" L] and MOC of all Equipment's are made by SS 316 Material. Section [B] includes Pressure Transmitter [0-40 Bar] and Temperature Transmitter [0$\left.150{ }^{\circ} \mathrm{C}\right]$. Section [C] includes one Needle Valve. Section [D] involves PLC Panel box made up of SS 304.Section [E] includes permeate Line made by Silicon flexible Material. Figure 2 shows the photographs of pilot plant. Feed Concentration of $1 \mathrm{ppm}$ and operating pressure at 1 and 2 bar respectively were selected for the nanofiltration experiment using spiral coil module [3]. The volume of feed solution was $5 \mathrm{l}$ in the feed tank. Initially the distilled water flux was calculated as basis to get the permeability of the membrane. Basically, the membrane was getting chocked due to accumulation of solute dye particles and then by means of various cleaning agents [Chemical treatment] successive cleaning can be performed. The experiment involves one chemical agent i.e. $5 \% \mathrm{NaOH}$ solution. All the experiments were conducted at the prevailing ambient temperature.

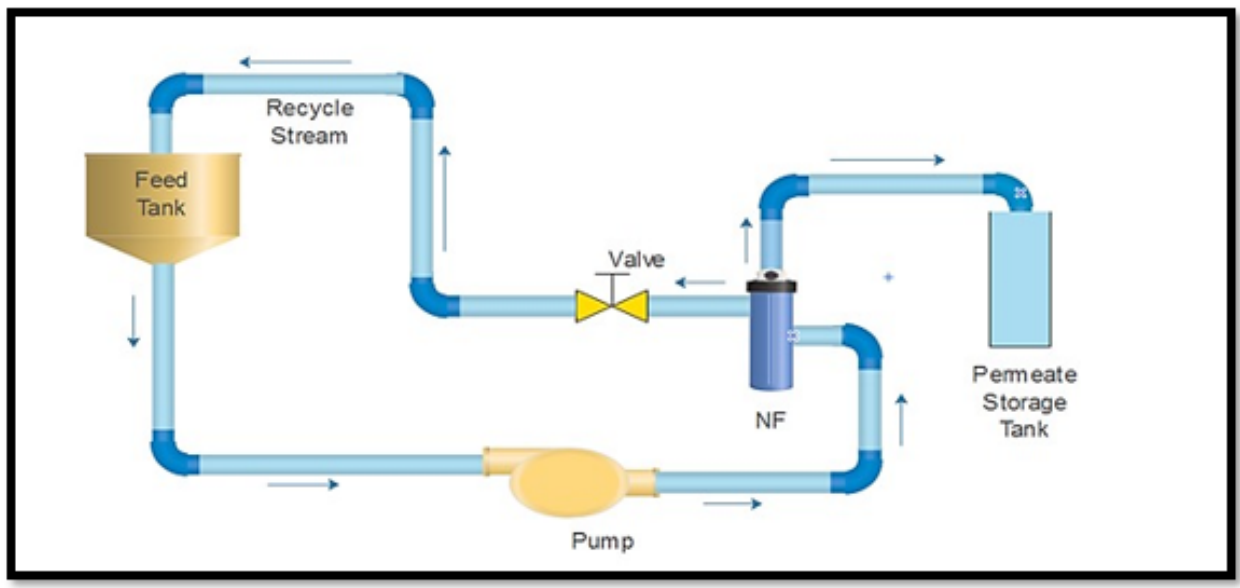

Figure 1: Schematic of experimental set-up of nanofiltration.
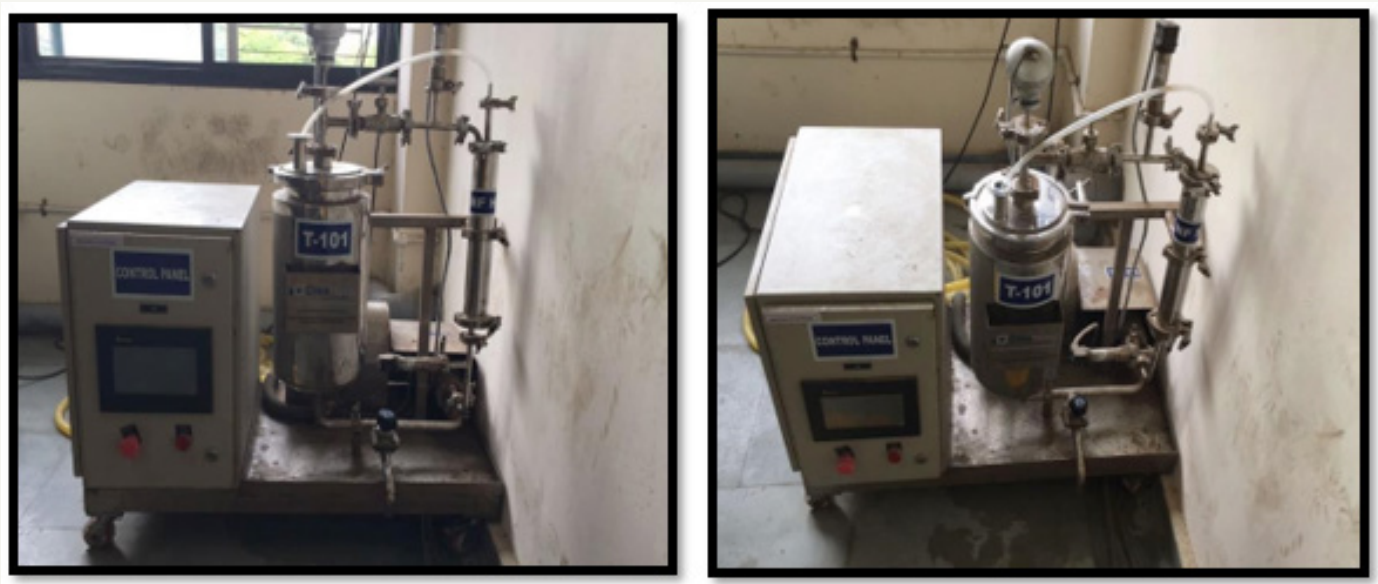

Figure 2: Photograph of NF pilot plant.

\section{Results and Discussion}

\section{Membrane permeate flux}

Two factors that characterize the membrane separation processes are Permeate flux and \% separation component. There are various direct and indirect factors that affect the permeate flux like feed transmembrane pressure, feed concentration, solute particles size, cross-flow velocity $[\mathrm{CVF}]$ etc. Permeability of membrane is calculated based on series of experimental run conducted using pure distilled water [4]. At different pressure values [ 1 bar and 2 bar], flux was calculated, and average permeate flux vs pressure graph plot give the slope depicting the membrane permeability value which turns to be $3.12 \times 10^{-11} \mathrm{~m}^{3} / \mathrm{m}^{2} \mathrm{~s} P a$, which remains almost unchanged during the whole experimental run.

\section{Fouling strategies}

For the effective cleaning strategic study and keen observation, membrane surface needs to be fouled with various foulants which can adhere on the surface layer by layer and increases the various resistances creating the system less efficient. This experimental body includes fouling of membrane surface by Fluorescein dark red dye [commonly used in microscopy, as dye laser, in forensics to detect latent blood stains, and in dye tracing]. Continuous flow of dye solution reduces the membrane efficiency in terms of solute rejection, flux enhancement and so on. At 1 bar pressure with $1 \mathrm{ppm}$ concentration solution passed through the membrane module compartment, there is definite decrease in the permeate flux as obvious due to being pressure driven process. The permeate flux 
will always decrease with time but the declination is compared keeping the time as major factor. The declination of permeate flux after $60 \mathrm{~min}$ run is $1.94 \times 10^{-8} \mathrm{~m}^{3} / \mathrm{m}^{2} \mathrm{sec}$ Figure 3. Similarly, the results were observed for the 2-bar pressure keeping the dye solution concentration same $[1 \mathrm{ppm}]$. The permeate flux declination here is $2.16 \times 1010^{-8} \mathrm{~m}^{3} / \mathrm{m}^{2}$ sec Figure 4. It is obvious that NF is pressure driven process and w.r.t time and alleviation in pressure, permeate flux declination will also increase [5].

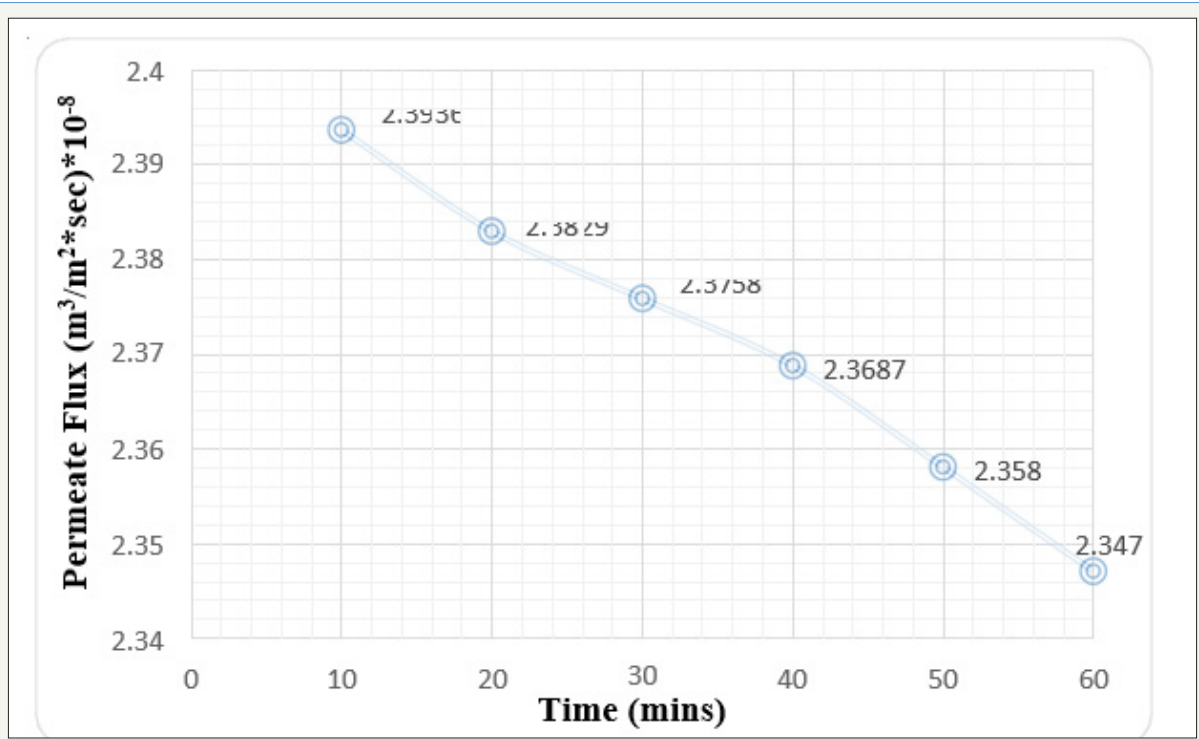

Figure 3: Graph of Permeate flux v/s time at 1 bar pressure keeping $1 \mathrm{ppm}$ concentration (Before Cleaning).

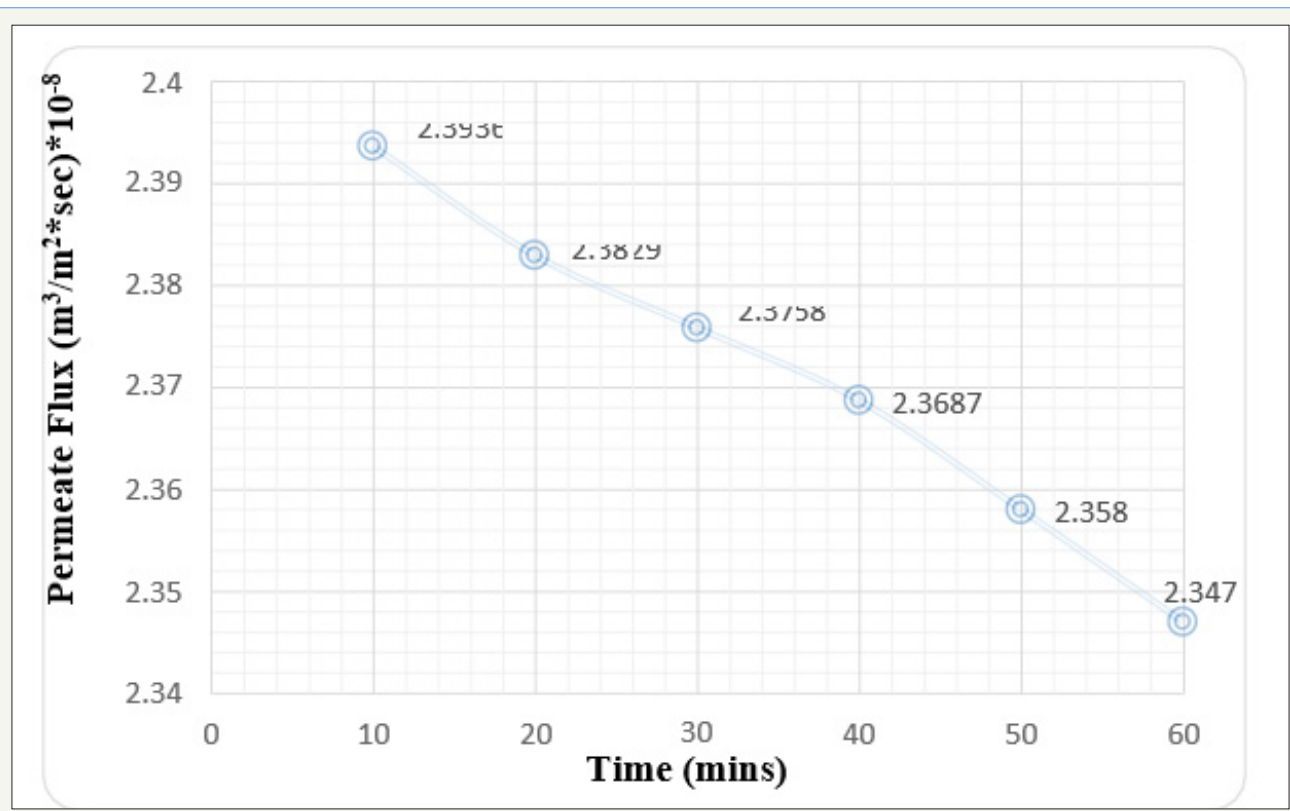

Figure 4: Graph of Permeate flux v/s time at 2 bar pressure keeping $1 \mathrm{ppm}$ concentration (Before Cleaning).

\section{Process of cleaning}

Due to solute red particles fouled on the membrane surface while performing the fouling process, it is mandatory for the upper layer to be cleaned to alleviate the membrane flux and permeability capacity. Various chemical cleaning agents are reviewed, and study revealed $\mathrm{NaOH}$ to be more capable agent for the throughput cleaning. For the cleaning of membrane $5 \% \mathrm{NaOH}$ solution was prepared in the laboratory. The cleaning time kept was 30 minutes and consecutive permeate flux was calculated again by passing the $1 \mathrm{ppm}$ at 1 and 2 bar pressure respectively. The observed results were plotted in the form of permeate flux vs time graph depicting the declination of permeate flux value as $1.33 \times 1010^{-8} \mathrm{~m}^{3} / \mathrm{m}^{2} \mathrm{sec}$ Figure 5 which is comparatively less than $1.94 \times 1010^{-8} \mathrm{~m}^{3} / \mathrm{m}^{2} \mathrm{sec}$ Figure 3 at 1 bar pressure. There is an alleviation of nearly 31.44 $\%$ in the permeate flux recovery which is very promising results. At 2 bar pressure, similar experiment was performed and nearly $1.14 \times 1010^{-8} \mathrm{~m}^{3} / \mathrm{m}^{2}$ sec [Figure 6] permeate flux is obtained which is very less compared to $2.16 \times 1010^{-8} \mathrm{~m}^{3} / \mathrm{m}^{2}$ sec Figure 4 . There is increase of approximately 47.22 permeate flux recovery when performed the cleaning by $\mathrm{NaOH}$ reagent. 


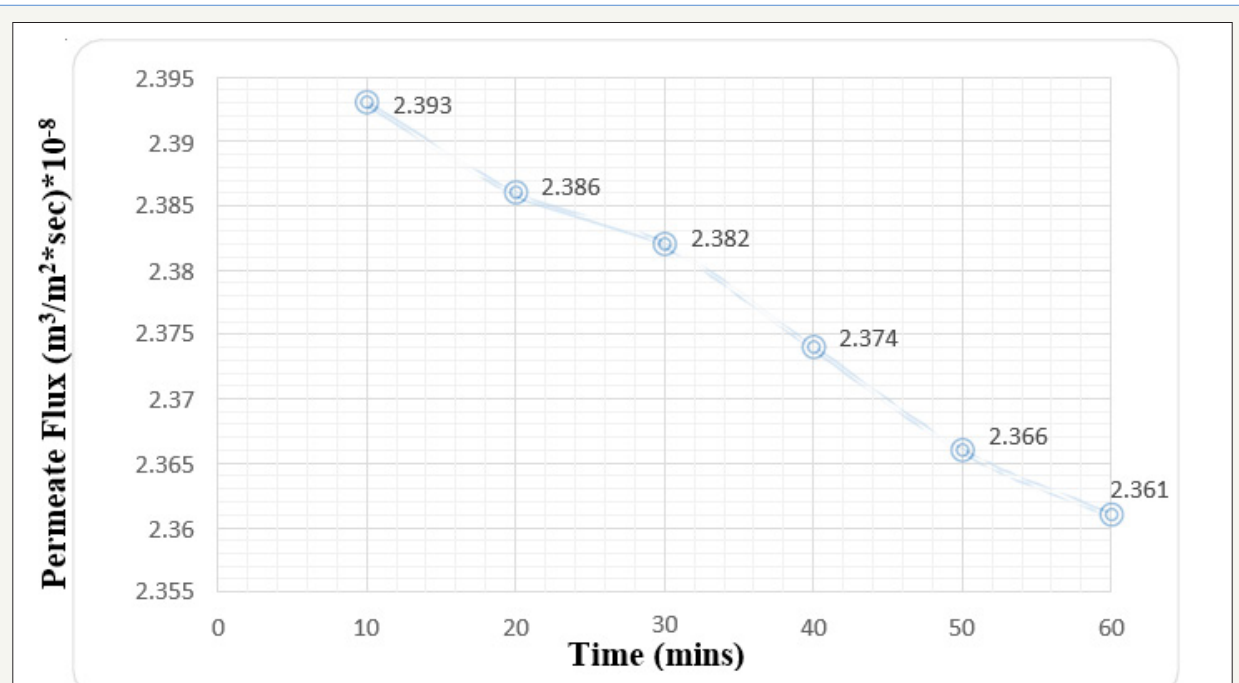

Figure 5: Graph of Permeate flux v/s time at 1 bar pressure keeping 1 ppm concentration (After Cleaning by $5 \% \mathrm{NaOH}$ solution).

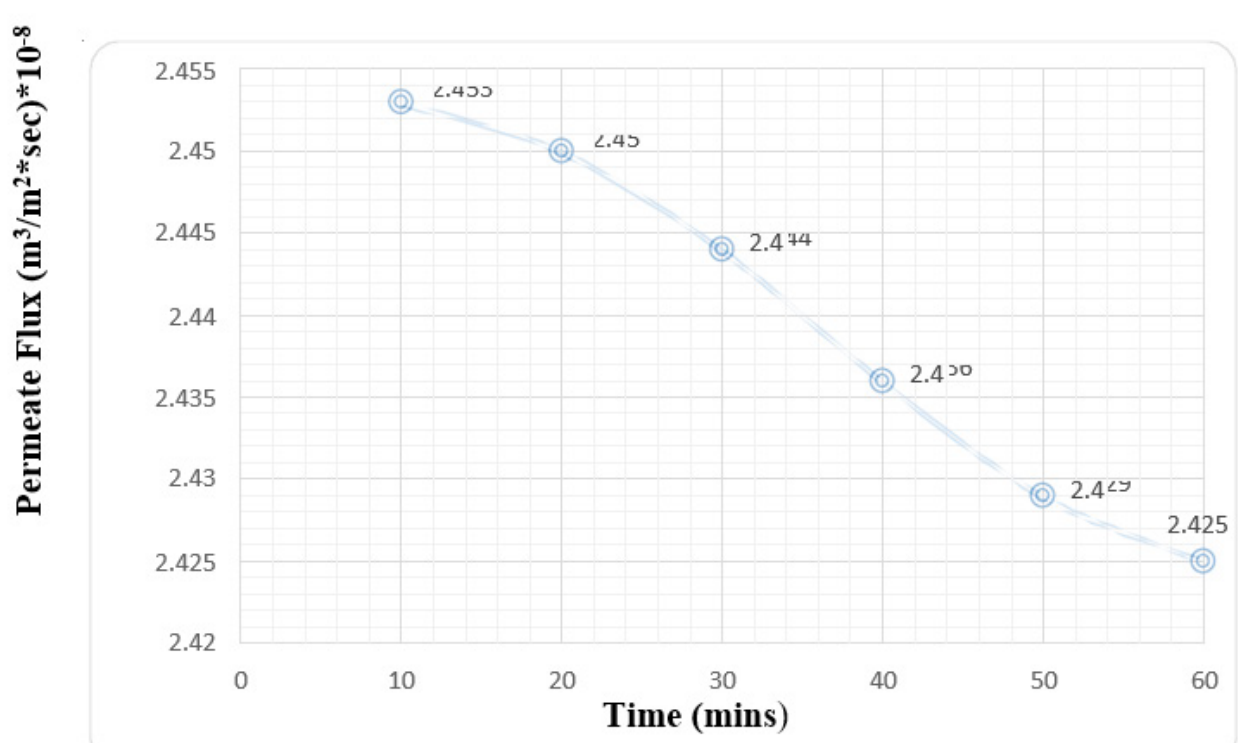

Figure 6: Graph of Permeate flux v/s time at 2 bar pressure keeping $1 \mathrm{ppm}$ concentration (After Cleaning by $5 \% \mathrm{NaOH}$ solution).

\section{Conclusion}

Concentration polarization and fouling is major drawback to membrane separation processes. This phenomenon make the separation difficult and ultimately increases the operation cost as membrane is having life span after the continuous usage. Although concentration polarization [CP] is reversible, fouling is permanent to some extent due to the deposition or adsorption of solutes on the membrane surface and pore blocking of the membrane. Fouling can be avoided and reduced to some extent by various cleaning reagents. $\mathrm{NaOH}$ found to be very effective cleaning agent when applied on Nanofiltration module at different pressures. For two different pressure [ 1 and 2 bar respectively] with same concentration [ $5 \%$ $\mathrm{NaOH}$ solution], increase is permeating flux recovery is around 31.44 and $47.22 \%$ keeping membrane permeability as base. Permeate flux recovery is more when higher pressure is applied. Results reveals that adhere solute particles can also be removed or cleaned to major extent by using $\mathrm{NaOH}$ as cleaning reagent moldings the system at different pressure and for specific interval of time.

\section{References}

1. Yin N, Zhong Z, Xing W (2013) Ceramic membrane fouling and cleaning in ultrafiltration of desulfurization wastewater. Desalination 319: 92-98.

2. Wang Z, Meng F, He X, Zhou Z, Huang LN, et al. (2014) Optimisation and performance of $\mathrm{NaClO}$-assisted maintenance cleaning for fouling control in membrane bioreactors. Water Res 53: 1-11.

3. Goode KR, Asteriadou K, Robbins PT (2013) Fouling and cleaning studies in the food and beverage industry classified by cleaning type. Comprehensive Reviews in Food Science and Food Safety 12(2): 121-143.

4. Espinasse BP, Chae S, Marconnet C (2012) comparison of chemical cleaning reagents and characterization of foulants of nanofiltration membranes used in surface water treatment. Desalination 296:1-6.

5. Ahmad AL, Mat Yasin NH, Derek CJC (2014) chemical cleaning of a crossflow microfiltration membrane fouled by microalgal biomass. Journal of the Taiwan Institute of Chemical Engineers 45(1): 233-241. 
Creative Commons Attribution 4.0 International License

For possible submissions Click Here

\section{Research \& Development in Material Science}

\section{Benefits of Publishing with us}

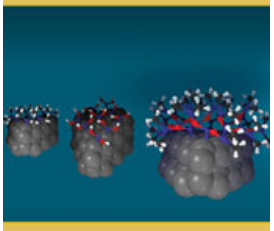

- High-level peer review and editorial services

- Freely accessible online immediately upon publication

- Authors retain the copyright to their work

- Licensing it under a Creative Commons license

- Visibility through different online platforms 